\title{
Shrinkage of thyrotrophin secreting pituitary adenoma treated with octreotide
}

\author{
S.M. Orme, J.T. Lamb' ${ }^{1}$ M. Nelson' ${ }^{1}$ and P.E. Belchetz
}

Departments of Endocrinology and 'Neuroradiology, The General Infirmary at Leeds, Great George Street, Leeds LS1 3EX, UK

\begin{abstract}
Summary: Thyrotrophin secreting pituitary adenomas are a rare cause of recurrent thyrotoxicosis. We report on a 47 year old woman with an 8-year history of this condition. In this case the somatostatin analogue, octreotide, normalized thyroid hormone levels. It was associated with marked tumour shrinkage, with striking reduction of the suprasellar extension and improved appearances in the region of the left cavernous sinus shown by high resolution computerized tomography. Following surgery she developed a biochemical relapse which responded to the reinstitution of octreotide. On long term treatment she developed stomach cramps and gallstones. Octreotide was discontinued. We review previous reports of this condition and discuss the role of octreotide in its management.
\end{abstract}

\section{Introduction}

Thyrotrophin secreting pituitary adenomas (TSHomas) are aggressive tumours which respond inadequately to surgery and radiotherapy. ${ }^{1}$ They are often diagnosed late as a consequence of initial misdiagnosis and inappropriate therapy. These tumours may therefore become large, and surgical extirpation is usually incomplete. ${ }^{1}$ We report a case in which octreotide proved a useful adjunctive therapy. We review the literature and describe tumour shrinkage with octreotide, which has not been previously reported in this condition.

\section{Case report}

A 47 year old woman presented in 1980 with clinical and biochemical evidence of thyrotoxicosis. In January 1981 she underwent a subtotal thyroidectomy. The histology showed no stigmata of autoimmune thyroid disease and no lymphocytic infiltration. By September 1981 she developed a low total thyroxine (T4) and was placed on Lthyroxine. Despite normalizing T4 at $139 \mathrm{nmol} / \mathrm{l}$ (reference range 60-140), thyroid stimulating hormone (TSH) remained high at $41 \mathrm{mU} / 1$ (reference range $0.2-6$ ). A computed tomographic (CT) scan suggested a pituitary tumour and a thyrotrophin secreting pituitary adenoma was diagnosed. Her thyroxine was increased to $200 \mu \mathrm{g}$ per day in an attempt to inhibit TSH release.

Correspondence: S.M. Orme, M.R.C.P.

Accepted: 26 November 1990
Between 1982 and 1987 tumour size increased on CT scan displacing and deforming the third ventricle. There was involvement of the left cavernous sinus and extension inferiorly into the sphenoid sinuses. Despite this she had no visual loss and the neurosurgeons elected to monitor her course. In 1987 thyroxine was withdrawn. She became clinically and biochemically thyrotoxic and was admitted for assessment. At that time her T4 was $167 \mathrm{nmol} / 1$, TSH $42 \mathrm{mU} / 1$ and alpha subunit $56.1 \mu \mathrm{g} / \mathrm{l}$ (reference range $0.5-2 \mu \mathrm{g} / \mathrm{l}$ ), with an alpha subunit/TSH molar ratio of 13.36 (reference range $0-1$ ). Normal TSH was not suppressed by bromocriptine.

She was commenced on carbimazole $15 \mathrm{mg} /$ day in June 1988, her T4 was $124 \mathrm{nmol} / 1$ and her TSH rose to $>50 \mathrm{mU} / 1$. In August she was reinvestigated. She underwent two day assessments in which thyroid hormones and TSH were estimated at regular intervals throughout the day. Initially she received $15 \mathrm{mg}$ of carbimazole at $09.00 \mathrm{~h}$ and 2 days later under identical conditions $15 \mathrm{mg}$ of carbimazole and $50 \mu \mathrm{g}$ of octreotide subcutaneously. Following carbimazole alone, TSH levels rose steadily, but when octreotide was administered simultaneously with carbimazole TSH levels fell progressively (Figure 1).

Subsequent chronic treatment with octreotide in a dose of $100 \mu \mathrm{g}$ three times a day resulted in suppression of thyroid hormones and TSH reaching a nadir of T4 $77 \mathrm{nmol} / 1$ and TSH $0.5 \mathrm{mU} / 1$. The effect of therapy on tumour size was evaluated using high resolution CT scanning with identical scanning protocols. This showed marked tumour shrinkage, with striking reduction of the suprasel- 


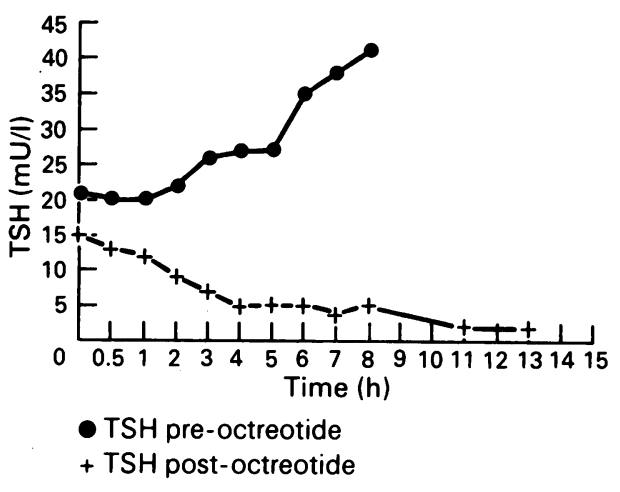

Figure 1 TSH day curve pre- and post-octreotide.

lar extension and improved appearances in the region of the left cavernous sinus (Figures 2 and 3).

In September 1988 she underwent transsphenoidal surgery. Tumour was found to be completely eroding the floor of the pituitary fossa and invading the sphenoid sinus. All macroscopic tumour was removed and the pituitary bed packed. Histology confirmed this to be a TSH secreting pituitary adenoma.

Three weeks later she was briefly readmitted with a transient third nerve palsy. At that time she was recommenced on L-thyroxine $100 \mu \mathrm{g} /$ day in an attempt to suppress TSH release when T4 was $234 \mathrm{nmol} / 1$ and TSH $52 \mathrm{mU} / 1$. Within a fortnight she developed a headache and complete left third, fourth and sixth cranial nerve palsies and was found to have a pseudoaneurysm of the left inferior siphonic portion of the left internal carotid artery. This was treated by balloon embolization.

At this time the L-thyroxine was discontinued and the biochemical relapse was treated by reintroducing octreotide. Following 5 days of treatment the T4 had fallen to $67 \mathrm{nmol} / 1, \mathrm{TSH}<2 \mathrm{mU} / 1$ and alpha subunit $<0.1 \mu \mathrm{g} / \mathrm{l}$. In summer 1989 she underwent external radiotherapy 4500 rads in 25 fractions over 5 weeks. Octreotide was stopped after 9 months due to the development of stomach cramps and gallstones. She is presently on no medication and her ophthalmoplegia is mild. In January 1990 her T4 was $158 \mathrm{nmol} / \mathrm{l}$, TSH $15 \mathrm{mU} / 1$ and alpha subunit $4.2 \mu \mathrm{g} / \mathrm{l}$.

\section{Discussion}

Thyroid stimulating hormone is a pituitary glycoprotein hormone with a molecular weight of approximately 28,000 Daltons. It is composed of two noncovalently linked subunits alpha and beta. Alpha subunit has an almost species-specific amino acid sequence which is common to the other

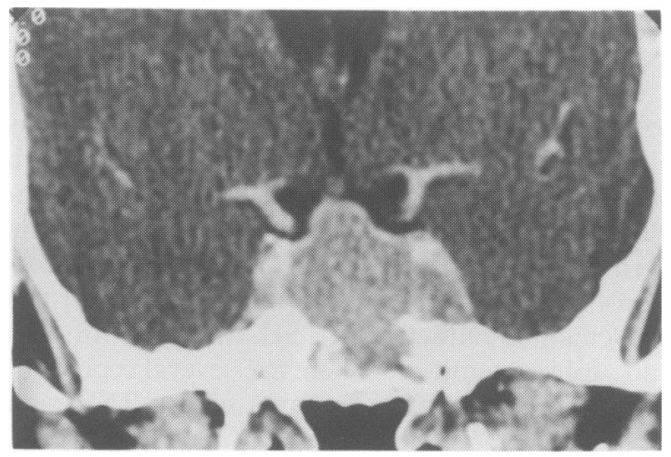

Figure 2 CT shows massive pituitary adenoma with supra sella extension, extending into the third ventricle, invading the left cavernous sinus and sphenoid bone (coronal contrast enhanced $3 \mathrm{~mm}$ sections).

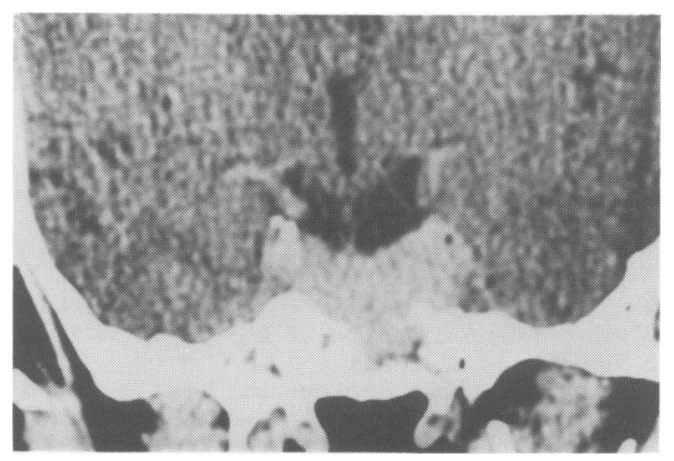

Figure 3 CT following 2 weeks of octreotide shows marked tumour shrinkage (coronal contrast enhanced $3 \mathrm{~mm}$ sections).

glycoprotein hormones FSH, LH and HCG. Beta subunit is unique to TSH and confers specific biological activity when combined with alpha subunit. ${ }^{2,3}$ TSH release and synthesis is predominantly mediated by TRH. Dopamine and somatostatin play an inhibitory role in the control of TSH secretion. ${ }^{2,3}$ Somatostatin is also thought to affect synthesis of thyrotrophin. ${ }^{4}$ Thyroid hormones exert a negative feedback effect on TSH release primarily at the pituitary level., ${ }^{2,3}$

Inappropriate TSH secretion can be due to a pituitary adenoma ${ }^{5}$ or partial pituitary insensitivity to thyroid hormone feedback. ${ }^{6}$ The latter condition can occur with or without insensitivity of the peripheral tissues to the effect of thyroid hormone. ${ }^{7}$ Pituitary thyrotrophin secreting adenomas secrete alpha subunit in molar excess, this is used as a diagnostic aid and to assess therapy. ${ }^{8}$ They tend to be macro adenomas which are incompletely resected at surgery and are not generally cured by radiotherapy. They also do not respond well to conventional antithyroid therapy, as rendering the 
patient hypothyroid allows the tumour to escape from possible feedback inhibition. ${ }^{9}$

For this reason treatment with thyroid hormone has been used, but with only limited success, as illustrated by the case we present. Treatment with bromocriptine and steroids has also been employed, ${ }^{10,11}$ but the results have been disappointing.

In several studies it has been shown that treatment with octreotide has resulted in clinical improvement, a reduction in TSH, thyroid hormones and alpha subunit. ${ }^{12,13}$ There are several reports of visual improvement in patients with a TSH-oma treated with octreotide prior to surgery. ${ }^{13,14}$ However, unlike in acromegaly, ${ }^{15}$ there are, to our knowledge, no previous reports of proven tumour shrinkage of a TSH-oma treated with octreotide. We feel that octreotide is of proven benefit in this condition. However, it does have some drawbacks including the development of cholelithiasis seen in our patient which is a recognized side effect. This is not surprising as it is known that somatostatin reduces gallbladder contractility and gallstones are a prominent feature of the syndrome associated with somatostatinomas. ${ }^{16}$

\section{References}

1. Hill, S.A., Falko, J.M., Wilson, C.B. \& Hunt, W.E. Thyrotrophin producing pituitary adenomas. J Neurosurg 1982, 57: 575-579.

2. Morley, J.E. Neuroendocrine control of thyrotrophin secretion. Endocrinol Rev 1981, 12: 396-436.

3. Weintraub, B.D., Gershengorn, M.D., Kourides, I.A. \& Fien, H. Inappropriate secretion of thyroid-stimulating hormone. Ann Intern Med 1981, 95: 339-351.

4. Gorden, P., Comi, R.J., Maton, P.N. \& Go, V.W. Somatostatin and somatostatin analogue (SMS 201-995) in treatment of hormone secreting tumours of the pituitary gastrointestinal tract and non-neoplastic diseases of the gut. Ann Intern Med 1989, 110: 35-50.

5. Emerson, C.H. \& Utiger, R.D. Hyperthyroidism and excessive thyrotrophin secretion. $N$ Engl J Med 1972, 287: $328-333$.

6. Gershengorn, M.C. \& Weintraub, B.D. Thyrotrophin induced hyperthyroidism caused by selective pituitary resistance to thyroid hormone. J Clin Invest 1975, 56: 633-642.

7. Elewaut, A., Mussche, M. \& Vermeulen, A. Familial target organ resistance to thyroid hormones. J Clin Endocrinol Metab 1976, 43: 575-581.

8. Kourides, I.A., Ridgway, E.C., Weintraub, B.D. et al. Thyrotrophin-induced hyperthyroidism use of alpha and beta subunit levels to identify patients with tumours. J Clin Endocrinol Metabol 1977, 45: 534-543.

9. Samaan, N.A., Osbourne, B.M., Mackay, B., Leavens, M.E., Duello, T.M. \& Halmi, N.S. Endocrine and morphologic studies of pituitary adenomas secondary to primary hyperthyroidism. J Clin Endocrinol Metab 1977, 45: 903-911.

10. Bevan, J.S., Burke, C.W., Esiri, M.M. et al. Studies of two thyrotrophin secreting pituitary adenomas evidence for dopamine receptor deficiency. Clin Endocrinol 1989, 31: 59-70.

11. Smallbridge, R.C. \& Smith, C.E. Hyperthyroidism due to thyrotrophin secreting pituitary tumours, diagnostic and therapeutic considerations. Arch Intern Med 1983, 143: 503-507.

12. Comi, R.J., Gesundheit, N., Murray, L., Gorden, P. \& Weintraub, B.D. Response of thyrotrophin secreting pituitary adenomas to a long acting SMS-analogue. $N$ Engl $J$ Med 1987, 317: 12-17.

13. Beck-Peccoz, P., Mariotti, S., Guillausseau, P.J. et al. Treatment of hyperthyroidism due to inappropriate secretion of thyrotrophin with somatostatin analogue SMS 201-995. Clin Endocrinol Metab 1989, 68: 208-214.

14. Guillausseau, P.J., Chanson, P.H. \& Timsit, J. Visual imper rovement with SMS 201-995 in a patient with a thyrotrophin secreting pituitary adenoma. $N$ Engl $J$ Med 1987,317 : 53- 54 .

15. Barkan, A.L., Lloyd, R.V., Chandler, W.F. et al. Preoperative treatment with long acting somatostatin analogue SMS 201-995, shrinkage of invasive pituitary macroadenomas and improved surgical remission rate. J Clin Endocrinol Metab 1988, 67: 1040-1048.

16. Krejs, G.J., Orci, L., Conlon, J.M. et al. Somatostatinoma syndrome, biochemical, morphologic and clinical features. $N$ Engl J Med 1979, 301: 285-292. 